\title{
OPTIMAL CONTROL OF THE ELECTRIC SHIPS' PROPULSION MOTORS DURING REVERSAL
}

Introduction. Reliability and safety of electric ships' maneuverability depends on the maneuvering characteristics of their propulsion motors (PM). Therefore, the issues of improving the process of controlling propulsion motors at maneuvers are topical. The aim of this paper is to find the optimal laws of control. The indicators estimating electric ships' maneuvering properties are chosen as criteria of optimality. Methodology. A proportional control law is traditionally used in electrical propelling plants with frequency-controlled PM. However, it does not provide the necessary maneuvering characteristics to the electric ships, since it does not take into account the process of the vessel's movement. To search for the optimal control laws of propulsion motors at maneuvers, the electrical propulsion plant is considered in unity with all the components of the ship's propulsion complex. The dimensionless parameters of the complex are revealed from the mathematical model of the transient modes of its operation. They determine the numerical values of the optimality criteria. Control signals are formed by frequency and voltage. A method for the formation of optimal control laws is proposed. The nature of the target functions is revealed and a special optimization method is developed. A minimum of the braking distance and a minimum of energy spent on maneuvering are taken as criteria of optimality. Results. The parameters of the complexes that significantly affect the optimality criteria are revealed. For various combinations of the values of these parameters, optimization calculations have been carried out and the optimal control laws of the propulsion motors during electric ships' reversal have been found. Optimization is carried out by the criterion of the minimum of the braking distance and by the criterion of minimum energy consumption. The results are presented in an analytical form and in a graphical form. The effectiveness of the proposed control laws is illustrated. Scientific novelty. The method of searching for the optimal control laws of the propulsion motors is constructed according to the system principle. This allows us to find the control laws of the propulsion motors on the final result - on the indicators of electric ships' maneuverability. The proposed recommendations cover a wide class of vessels with electric motion. Practical value. The proposed optimal control laws for propulsion motors can be used both in the design of propulsion power plants and in their operation. The best control law can be selected and incorporated into the control system for any particular electric ship of the considered class, depending on the quality of maneuvering. In particular, the optimal control law for propulsion motors during reversal providing electric ship's minimum braking distance or minimum energy consumption for maneuvering can be chosen. References 9, tables 4, figures 3 .

Key words: control of propulsion motors during electric ships' maneuvers, optimization method, optimal control laws.

Целью работы является поиск оптимальных законов управления гребными электродвигателями (ГЭД) судов с электродвижением. Критериями оптимальности выбраны показатели, характеризующие маневренные свойства электроходов. Методика. Пропорциональный закон управления ГЭД не обеспечивает нужные маневренные свойства электроходам. Оптимальные законы управления ГЭД, обеспечивающие наилучиие маневренные характеристики электроходов могут быть найдены при совместном рассмотрении гребной электроэнергетической установки, гребных винтов и корпуса судна. Результаты. Предложен новый способ формирования оптимальных законов управления. Выявлен характер целевых функций и разработан метод оптимизации. Проведены оптимизационные расчеты и найдены оптимальные законы управления гребными электродвигателями при реверсе электроходов. Оптимизация проведена по критериям минимума тормозного пути и минимума расхода энергии. Проиллюстрирована эффективность использования предлагаемых законов управления. Научная новизна. Метод поиска оптимальных законов управления построен по системному принципу. Это позволяет находить законы управления гребными электродвигателями по конечному результату - по показателям судна. Практическая значимость. Предложенные рекомендации могут использоваться как при проектировании гребных электроэнергетических установок, так и при их эксплуатации. Для конкретного электрохода, в зависимости от показателей качества маневрирования, может быть выбран (из предложенных) и заложен в систему регулирования наилучиий закон управления гребными электродвигателями. Библ. 9, табл. 4, рис. 3.

Ключевые слова: управление гребными электродвигателями электроходов на маневрах, метод оптимизации, оптимальные законы управления.

Relevance of the problem. A distinctive feature of vessels with electric propulsion is that maneuverable modes - acceleration, braking, reverse, exit to circulation - are for them the main operational modes of operation. The high maneuverability of electric ships is one of the main qualities that determined the reason for such a high interest in the use of modern electric propulsion systems on ships and warships. Not surprisingly, special attention is paid to the reliability and safety of maneuverable operations.

The results of a comparative analysis show that electrically-powered vessels have significantly better maneuverability characteristics than vessels with traditional types of power plants. The most important maneuver for electric ships is the reverse of propulsion electric motors. In particular, for the majority of vessels with power plants with direct transfer of torque of primary engines to propellers, the reversal process is protracted and lasts 1-2 minutes. The duration of the reverse of the propulsion motors (PMs) rarely exceeds 15-20 s (for example, for the "Arktika» atomic electric ship, the reverse time from «full forward» to «full back», when the power limiter is $100 \%$, is about $30 \mathrm{~s}$ ). The procedure for reversing internal combustion engines is incomparably more complicated compared to the reverse

(C) V.A. Yarovenko, P.S. Chernikov, R.A. Varbanets, E.I. Zaritskaya 
of the PM. In addition, not every reverse can be successful. Namely, due to the late maneuvering leading to an additional run-down of the vessel, up to $40 \%$ of ship collisions occur. Thus, even such a brief comparison shows that propulsion power plants (PPPs) provide higher reliability and safety of maneuvering operations.

One of the promising options for the construction of a PPP is an electromotive system based on induction frequency-controlled propulsion motors. In this regard, the issues of improving the control of propulsion electric motors for PPP during maneuvers are highly relevant. Moreover, the need to evaluate the maneuvering properties of electric ships and to search for the best laws for controlling the propulsion electric motors during maneuvers arises both at the initial stages of their design and during the operation of ships.

When searching for the best PM control laws, the criteria for evaluating them should, first of all, be indicators that evaluate the performance of the vessel itself, as the «older» system. This is the only way to ensure a systematic approach to the selection of optimal control laws for propulsion electric motors during maneuvers.

The state of the issue considered. In relation to the propulsion electric power plants with frequency-regulated PMs, the optimal control law, borrowed from the theory of frequency control of general industrial electric drives ( $\gamma / \alpha=$ const), has traditionally been proposed. Here $\gamma$ is the relative voltage $\gamma=U / U_{n}, \alpha$ is the relative frequency $\alpha=f / f_{n}$. However, it should be remembered that the recommended proportional optimal control law was obtained in relation to the «electrical» performance indicators of electric motors. At a systematic approach, these indicators fade into the background. There is a need to search for the laws of control that will provide the best values of the quality indicators of an electric ship's maneuvering, with controlled (with specified tolerances) performance of propulsion electrical installation, too.

In accordance with the defined task, the analysis of the operation of PPPs on maneuvers should be carried out in conjunction with all the components of the propulsion complex of the electric ship, including the ship electric power installation (primary engines, electric current generators, electric power converters, PMs), propellers, steering wheel and ship hull. Only in this formulation we can carry out a thorough analysis of the maneuverable modes of operation, assess the maneuverability properties of the electric ship and find the optimal PM control laws that provide the best maneuverability of the vessel.

In [1], attempts were made to find the optimal laws of control of the propulsion motors of electric ships when performing maneuverable operations. For this purpose, a mathematical model of the transient operating modes of the propulsion electrical installation was developed as part of a single ship propulsion complex. Based on the model, algorithms for calculating transient modes are developed and a method for finding optimal control laws is proposed. But:

- when describing the processes occurring in heat engines of the propulsion electric power plant, a number of assumptions were adopted that do not allow controlling the dynamic indicators of their operating modes;

- a mathematical description of the processes occurring in synchronous generators was built on the basis of a vector diagram of the generator, which also made it impossible to fully evaluate their dynamics, and led to certain errors in assessing the dynamic performance of the PPP;

- the proposed type of voltage control laws, as shown by the results of the analysis, does not fully satisfy the tasks set.

In order to search for control laws for propulsion electric motors that, on the one hand, provide the best values of quality indicators for maneuvering, and, on the other hand, allowable dynamic loads on the propulsion electrical installation and heat engines of the ship power plant, it is necessary to improve the mathematical model and clarify the type and procedure for finding optimal control laws. It is proposed to accept as the main indicators of the quality of maneuvering (as an example of solving such problems) the minimum stopping distance of the vessel or the minimum energy (fuel consumption costs) to perform the maneuver. The choice of the indicator is determined by the goals and conditions of the maneuver.

The goal of the paper is to find the optimal laws of control of the propulsion electric motors, ensuring high maneuverability properties of the electric ships.

The method of solving the problem. In [2], a refined mathematical model of the transient modes of the propulsion electric power installations of electric ships as part of ship propulsion complexes was proposed. In it:

- isodromic all-mode regulators of indirect action were considered as regulators of the speed of rotation of heat engines; as voltage regulators of synchronous generators, combined (by the control action and by the deviation of the controlled variable) regulators are considered;

- transients in the speed regulators of rotation of heat engines are described taking into account rigid and flexible feedbacks, and taking into account the operation of the active power distribution system (with parallel generating units);

- transients in synchronous generators are represented by the Park-Gorev equations;

- the composition of the combined system of automatic voltage regulation of synchronous generators includes a circuit for regulating the distribution of reactive power (with parallel generating units).

To give generality to the results of calculations, the model is reduced to relative units. As a result, the criteria of dynamic similarity (dimensionless parameters) of the propulsion complexes «heat engines - propulsion electric installation - propulsions - steering - ship hull» were revealed. Possible ranges of variation of their values are found. It is these parameters that determine the current, in the course of the execution of the maneuver, the values of performance indicators of all components of the complex and directly affect the numerical values of the indicators of the quality of maneuver. For the calculation of maneuvering modes a package of application programs is 
developed. Basic is a program that allows to calculate the current values of the relative performance indicators.

This approach allows to give generality to the obtained results - electric ships with equal values of dimensionless parameters will have respectively the same values (in relative units) of the quality indicators of maneuvering.

The composition of the power plant includes several power circuits (by the number of propulsion motors). Usually there are two-three of them. Each circuit (each $\mathrm{PM}$ ) is controlled independently of the others from the control station (CS) located on the bridge. In this case, two control signals are formed on the frequency converter: by the relative frequency $\alpha$ and by the relative voltage $\gamma$.

It is proposed to generate control signals by the relative frequency $\alpha=\alpha(T)$ and by the relative voltage $\gamma=\gamma(\alpha)$ in the form:

$$
\begin{gathered}
\alpha=\alpha_{\text {prim }}+K_{1}\left(1-\exp \left(-K_{5} T\right)\right) ; \\
\gamma=K_{2} \alpha+K_{3} \alpha^{2}+K_{4} \alpha^{3}+\left(1-K_{2}-K_{3}-K_{4}\right) \alpha^{4},
\end{gathered}
$$

where $\alpha_{\text {prim }}$ is the initial value of the relative frequency of the PM supply voltage; $T=\frac{v_{0} t}{L}$ is the dimensionless time; $v_{0}$ is the steady state speed of the vessel; $L$ is the vessel length; $t$ is the current time; $K_{1}, K_{2}, K_{3}, K_{4}, K_{5}$ are the optimized factors.

The need for an initial non-zero $\alpha_{\text {prim }}$ becomes apparent from a comparison (Fig. 1) of the reverse characteristics of the propeller (curve 2) with the mechanical characteristics of the induction PM with the opposite direction of rotation of the magnetic field (curves 1).

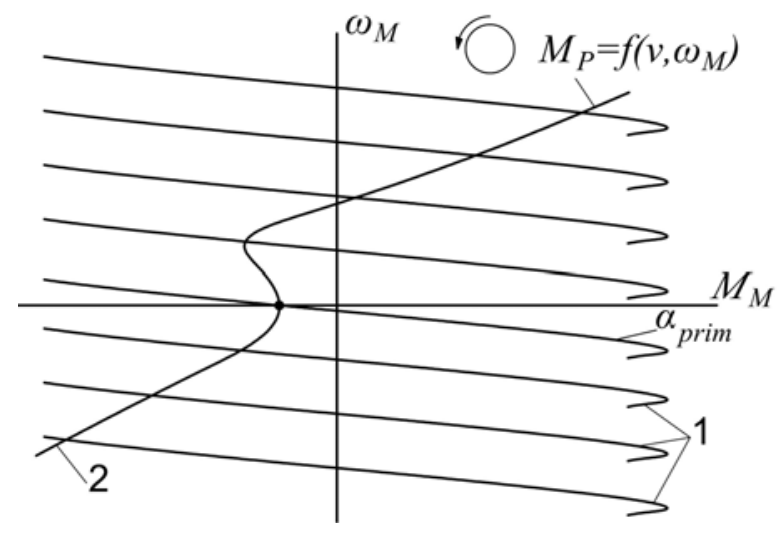

Fig. 1. Reversible propeller characteristic and mechanical characteristics of PM

Optimization of the control laws should be carried out according to the rate of change of the relative frequency (depending on the shift of the CS handle) and according to the relative voltage $\gamma=\gamma(\alpha)$. criteria:

The following criteria were selected as optimality

- minimum stopping distance $-L_{T \min }$; $L_{T \text { min }}$.

- minimum energy losses to perform the maneuver -

The problems to be solved belong to the field of nonlinear programming and consist in finding the extrema of the target function $f(x)$ under given constraints $g_{j}(x)$ in the form of inequalities. In other words, it is necessary to minimize some objective function.

$$
f(x), x \in E^{n}
$$

with $p$ linear constraints in the form of inequalities

$$
g_{j}(x) \geq 0, j=1, \ldots, p
$$

where $E^{n}$ is the admissible domain of the $n$-dimensional space.

The optimal solution is a pair $x^{*}$ and $f\left(x^{*}\right)$ consisting of the optimal point $x^{*}=\left[x_{1}^{*}, x_{2}{ }^{*}, \ldots, x_{n}^{*}\right]$ and the corresponding value of the target function $f\left(x^{*}\right)$.

The objective choice of the optimal solution variant requires the use of a quantitative complex criterion that takes into account, for each version of the ship electric power installation, a set of heterogeneous indicators of the quality of operation and the corresponding costs.

In the course of optimization calculations, problems of both single-criterion and multi-criteria optimization can be solved. In the first case, one of the quality indicators serves as the target function. In the second case, the objective function is constructed as

$$
f(x)=\sum m_{j} f_{j}(x),
$$

where $m_{j}$ is the weight coefficient of the $j$-th quality indicator.

In accordance with the goals set in the paper, either the minimum stopping distance of the vessel $L_{T \min }$, or the minimum energy losses on the execution of the maneuver $W_{\text {min }}$ are taken as the criteria for optimality. All other criteria fade into the background and are taken into account in the form of restrictions (4). Thus, in this paper, single-objective optimization problems were solved. There is no need to estimate weight coefficients.

Procedures for finding optimal solutions were based on the identified nature of the target functions. As shown by numerous calculations, they are multi-extremal, with an unknown number of points of local minima. Therefore, global optimization methods were used as the basis for algorithms for finding optimal solutions.

It is known that the existing classical optimization methods [4-6], as a rule, are not suitable for solving real practical optimization problems. We need special methods that take into account the specifics and nature of the target functions.

The values of $f(x)$ are found as a result of calculations of the maneuvers described by a complex system of algebraic and differential equations with numerous restrictions in the form of inequalities. It is just unrealistic to set the task of searching for the first and, moreover, the second derivative of the target functions.

A large number of preliminary calculations and their analysis showed that the target functions have the form of steep and elongated ravines. The analysis of existing methods of searching for global optima of such target functions gave grounds to lay the well-known, wellproven method of global random search - the random multi-start, as the basis for the developed global optimization algorithms.

In its pure form, a random multi-start is ineffective due to possible repeated descents to points of local minima. Therefore, a combination of one of the passive coating methods, the random grid method, with the modified tunnel algorithm method [1] was incorporated into the global optimization algorithm. 
When developing methods for searching for local minima (internal procedures of global optimization), it was again taken into account that the target functions have an implicitly gully character. On this basis, local optimum search algorithms were created based on a combination of local descent methods and ravine search methods. The methods of Powell and Nelder-Mead [7] turned out to be the most effective for solving such problems.

The ravine search for a local optimum was carried out as follows. Two local descents from nearby starting points were organized. We searched from each point for intermediate local minima $f_{1}^{*}\left(x_{1}^{*}\right)$ and $f_{2} *\left(x_{2} *\right)$. Then we found a new direction $s_{0}(*)$ drawn from $x_{1} *$ to $x_{2}{ }^{*}$ (or vice versa, depending on which of the found intermediate minima $f_{1}^{*}\left(x_{1}^{*}\right)$ or $f_{2}^{*}\left(x_{2}^{*}\right)$ is more), and along it we searched the minimum value of the function $f_{\text {opt.loc }}\left(x^{*}\right)$ which was the local optimum.

To solve the minimization problems, the optimization methods used were combined with the method of penalty functions [8], which made it possible to reduce the nonlinear programming problem with constraints to an equivalent sequence of problems without constraints.

The search for optimal control laws is carried out as follows. Each time, after setting a random starting point, the investigated maneuver is calculated and the corresponding values of the optimality criteria (in particular, the stopping distance or the energy losses for the maneuver) are found. Then, in accordance with the described procedure of movement to the optimum, new initial data (new values of optimized parameters) are calculated, the maneuver is calculated again and the corresponding values of the optimality criteria are found. The calculation ends when the global optimum is reached.

The developed mathematical apparatus allows to find the optimal laws of control of the propulsion electric motors during maneuvers.

Below we consider the search for the optimal control laws for the propulsion electric motors of electric ships during reverse. It was noted that the choice of quality indicators and, accordingly, the type of the target function of the optimization process is determined by the goals set and conditions of the maneuver. When operating in cramped conditions, the reverse (the quality of the reversal) directly affects the safety of maneuvering operations. In this case, the main criterion for optimality is the minimum stopping distance of the electric ship $L_{T \text { min }}$. If maneuvering is carried out in «calm» conditions, there are no other vessels or other objects nearby, the stopping distance of the electric ship fades into the background. In this case, as an optimality criterion, it makes sense to take the minimum energy losses on the execution of the maneuver $W_{\min }$. And in one, and in another case, it will be about single-criteria optimization tasks. The remaining indicators of the quality of maneuvering are taken into account in the form of restrictions (together with the settings of protection systems and restrictions ensuring the normal functioning of the propulsion complex). This is fully consistent with the principles of the systems approach [3].
For electric ships, the frequency-controlled stage of reversal of propulsion electric motors starts from the moment of time when the angular velocity of rotation of the PM passes through a zero value. This stage is characterized by intensive braking of an electric ship. It should be borne in mind that the propulsion motors at the same time operate in a very heavy mode, experiencing a large moment of resistance from the propellers, thereby significantly increasing the load on all the component parts of the propulsion electric power plant.

For each particular electric ship when performing maneuver operations, the optimal control laws will be different. At the same time, the proposed mathematical apparatus makes it possible to find the optimal control laws for a sufficiently large class of vessels. To do this, it is necessary to identify those dimensionless parameters of the complex that most significantly affect the control laws, find ranges of changes in their values (covering as much as possible the class of ships) and, after carrying out the necessary optimization procedures, find the optimal control laws for different combinations of these parameters. In other words - to find control laws for a whole class of vessels.

The results of the analysis of the influence of the initial conditions for the fulfillment of the maneuver and dimensionless parameters of the complex on the criteria $L_{T \min }$, and $W_{\min }$ carried out by methods of active planning of experiments [9], give grounds to consider the following as significant influencing parameters:

- $v_{\text {prim }}$ - initial vessel velocity;

- $N_{X}$ - power ratio of the electric ship

$$
N_{X}=\frac{L \sum K_{P j} P_{e j 0}}{\left(m+\lambda_{11}\right) v_{0}^{2}} ;
$$

- $C_{M 18}, C_{M 20}$ - dimensionless parameters of frequencycontrolled PM

$$
\begin{gathered}
C_{M 18}=\frac{c_{M}^{2}}{r_{2 M}^{\prime 2}} \alpha_{0}^{2} ; \\
C_{M 20}=\frac{\omega_{M 0}}{\omega_{1 M n}},
\end{gathered}
$$

where $P_{e j}$ and $K_{P j}$ are the useful stop of the propeller and its share in the total stop, respectively; $m$ is the vessel mass; $\lambda_{11}$ are the attached to the vessel the masses of water along its longitudinal axis; $\omega_{M}$ is the angular frequency of the PM rotation; $\omega_{1 M n}$ is the angular speed of rotation of the PM stator magnetic field; $r_{2 M}^{\prime}$ is the reduced $\mathrm{PM}$ rotor resistance; $c_{M}=x_{0 M} \tau_{M}$ is the constant design factor of frequency-controlled induction PM.

The results of the work. Table 1 presents the results of the search for optimal control laws for propulsion electric motors, providing the minimum braking distance of the electric ship $L_{T \text { min }}$ (the minimum stopping distance contributes to the safety of maneuver operations).

A series of optimization calculations were carried out for various combinations of values of significant dimensionless parameters. Different combinations of parameters are, in fact, nothing more than different electrical ships. 
Combinations of significant parameters and found optimal solutions by criterion $L_{T \min }$ (at $v_{\text {prim }}=0.3$ )

\begin{tabular}{|c|c|c|c|c|c|c|c|c|c|c|c|}
\hline \multirow{3}{*}{ Variant } & \multicolumn{3}{|c|}{$\begin{array}{l}\text { Values of significant } \\
\text { parameters }\end{array}$} & \multirow{3}{*}{$\begin{array}{l}L_{\text {Tclassic }} \\
\text { p.u. }\end{array}$} & \multicolumn{5}{|c|}{ Optimal solutions } & \multirow{3}{*}{$\begin{array}{l}L_{T \min } \\
\text { p.u. }\end{array}$} & \multirow{3}{*}{$\begin{array}{c}\text { Efficiency, } \\
\%\end{array}$} \\
\hline & \multirow[t]{2}{*}{$N_{X}$} & \multirow[t]{2}{*}{$C_{M 18}$} & \multirow[t]{2}{*}{$C_{M 20}$} & & \multicolumn{2}{|c|}{$\begin{array}{c}\text { equations } \\
\alpha=\alpha(T)\end{array}$} & \multicolumn{3}{|c|}{ equations $\gamma=\gamma(\alpha)$} & & \\
\hline & & & & & $K_{1}$ & $K_{5}$ & $K_{2}$ & $K_{3}$ & $K_{4}$ & & \\
\hline 1 & 0.12 & 15.7 & 0.88 & 0.43 & 0.57 & 7.03 & 0.99 & 0.26 & 1.35 & 0.36 & 16.3 \\
\hline 2 & 0.165 & 15.7 & 0.88 & 0.403 & 0.57 & 7.59 & 1.17 & 0.22 & 1.28 & 0.33 & 18.1 \\
\hline 3 & 0.21 & 15.7 & 0.88 & 0.365 & 0.56 & 6.75 & 1.02 & 0.27 & 1.32 & 0.31 & 15.1 \\
\hline 4 & 0.12 & 43.9 & 0.88 & 0.437 & 0.57 & 6.98 & 1.32 & -0.19 & 1.33 & 0.35 & 19.9 \\
\hline 5 & 0.165 & 43.9 & 0.88 & 0.406 & - & - & - & - & - & - & - \\
\hline 6 & 0.21 & 43.9 & 0.88 & 0.369 & 0.57 & 6.22 & 1.34 & -0.19 & 1.3 & 0.31 & 16 \\
\hline 7 & 0.12 & 72 & 0.88 & 0.444 & 0.6 & 6.89 & 1.19 & 0.2 & 0.89 & 0.35 & 21.2 \\
\hline 8 & 0.165 & 72 & 0.88 & 0.412 & 0.57 & 7.14 & 1.35 & 0.106 & 1.3 & 0.33 & 19.9 \\
\hline 9 & 0.21 & 72 & 0.88 & 0.373 & 0.6 & 6.2 & 1.2 & 0.2 & 0.87 & 0.3 & 19.6 \\
\hline 10 & 0.12 & 15.7 & 0.925 & 0.403 & 0.6 & 6.28 & 1.2 & 0.2 & 0.99 & 0.32 & 20.6 \\
\hline 11 & 0.165 & 15.7 & 0.925 & 0.378 & 0.6 & 6.12 & 1.85 & 0.24 & 1.33 & 0.3 & 20.6 \\
\hline 12 & 0.21 & 15.7 & 0.925 & 0.345 & 0.6 & 6.6 & 1.17 & 0.26 & 1.35 & 0.28 & 18.8 \\
\hline 13 & 0.12 & 43.9 & 0.925 & 0.407 & 0.62 & 6.14 & 1.2 & 0.19 & 0.74 & 0.32 & 21.4 \\
\hline 14 & 0.165 & 43.9 & 0.925 & 0.381 & 0.619 & 6.56 & 1.28 & 0.2 & 1.38 & 0.3 & 21.3 \\
\hline 15 & 0.21 & 43.9 & 0.925 & 0.348 & 0.61 & 6.6 & 1.18 & 0.22 & 1.05 & 0.28 & 19.5 \\
\hline 16 & 0.12 & 72 & 0.925 & 0.412 & 0.63 & 7.54 & 1.19 & 0.21 & 0.95 & 0.31 & 24.8 \\
\hline 17 & 0.165 & 72 & 0.925 & 0.385 & 0,63 & 6.49 & 1.2 & 0.2 & 0.93 & 0.3 & 22.1 \\
\hline 18 & 0.21 & 72 & 0.925 & 0.351 & 0.63 & 6.43 & 1.2 & 0.2 & 0.93 & 0.28 & 20.2 \\
\hline 19 & 0.12 & 15.7 & 0.97 & 0.38 & 0.64 & 6.46 & 1.19 & 0.2 & 0.86 & 0.28 & 26.3 \\
\hline 20 & 0.165 & 15.7 & 0.97 & 0.358 & 0.63 & 6.48 & 0.96 & 0.26 & 1.33 & 0.26 & 27.4 \\
\hline 21 & 0.21 & 15.7 & 0.97 & 0.328 & 0.639 & 6.487 & 0.968 & 0.263 & 1.332 & 0.261 & 20.4 \\
\hline 22 & 0.12 & 43.9 & 0.97 & 0.382 & 0.64 & 6.57 & 1.18 & 0.22 & 1.05 & 0.28 & 26.7 \\
\hline 23 & 0.165 & 43.9 & 0.97 & 0.361 & 0.65 & 6.47 & 1.2 & 0.2 & 0.86 & 0.27 & 25.2 \\
\hline 24 & 0.21 & 43.9 & 0.97 & 0.33 & 0.65 & 6.17 & 1.19 & 0.2 & 0.85 & 0.26 & 21.2 \\
\hline 25 & 0.12 & 72 & 0.97 & 0.386 & 0.65 & 5.82 & 1.36 & 0.2 & 0.76 & 0.29 & 24.9 \\
\hline 26 & 0.165 & 72 & 0.97 & 0.364 & 0.65 & 5.81 & 1.36 & 0.195 & 0.74 & 0.28 & 23.1 \\
\hline 27 & 0.21 & 72 & 0.97 & 0.332 & 0.656 & 5.886 & 1.365 & 0.192 & 0.745 & 0.258 & 22.3 \\
\hline
\end{tabular}

Table 1 shows a small part (as an example) of possible combinations of parameters. The variation in each parameter was carried out at three (minimum, medium and maximum) levels. For all combinations, the optimal control laws were found using the algorithm described above. (Similar tables were compiled for other initial values of vessel velocity $v_{\text {prim }}$. Optimal solutions were also found for them).

Also, in Table 1, for evaluating the effectiveness of the carried out optimization calculations, the values of the criterion $L_{T \min }$ are given, obtained by controlling PM using the «classical» law $\gamma / \alpha=$ const traditionally recommended for propulsion electric drives. This is the $L_{\text {Tclassic }}$ column. Comparison of the results obtained (see the last column of Table 1) clearly demonstrates the efficiency of using the calculated laws of optimal control.

Optimization results are conveniently presented graphically. As an example, in Fig. 2 the dependencies
$\alpha=\alpha(T), \gamma=\gamma(T)$ and $\gamma=\gamma(\alpha)$ are presented for the first three variants of the combination of parameters (for three electric ships). Analysis of the calculation results shows that the transition to the optimal (by $L_{T \min }$ ) control of the propulsion electric motors can significantly reduce the braking distance of the electric ship. Depending on the specific vessel (specific combinations of parameters of the complex), this reduction is in the range from $15 \%$ to $27 \%$.

The results obtained (in analytical form - the coefficients of optimal control laws $\alpha=\alpha(T)$ and $\gamma=\gamma(\alpha)$ in Table 1 and in graphic interpretation in Fig. 2) allow for any electric ship of the considered class to assign PM control laws that ensure the implementation of the «reverse» maneuver with a minimum stopping distance. If the dimensionless parameters of the electric ship differ from those given in the Tables, you can use any interpolation method. 

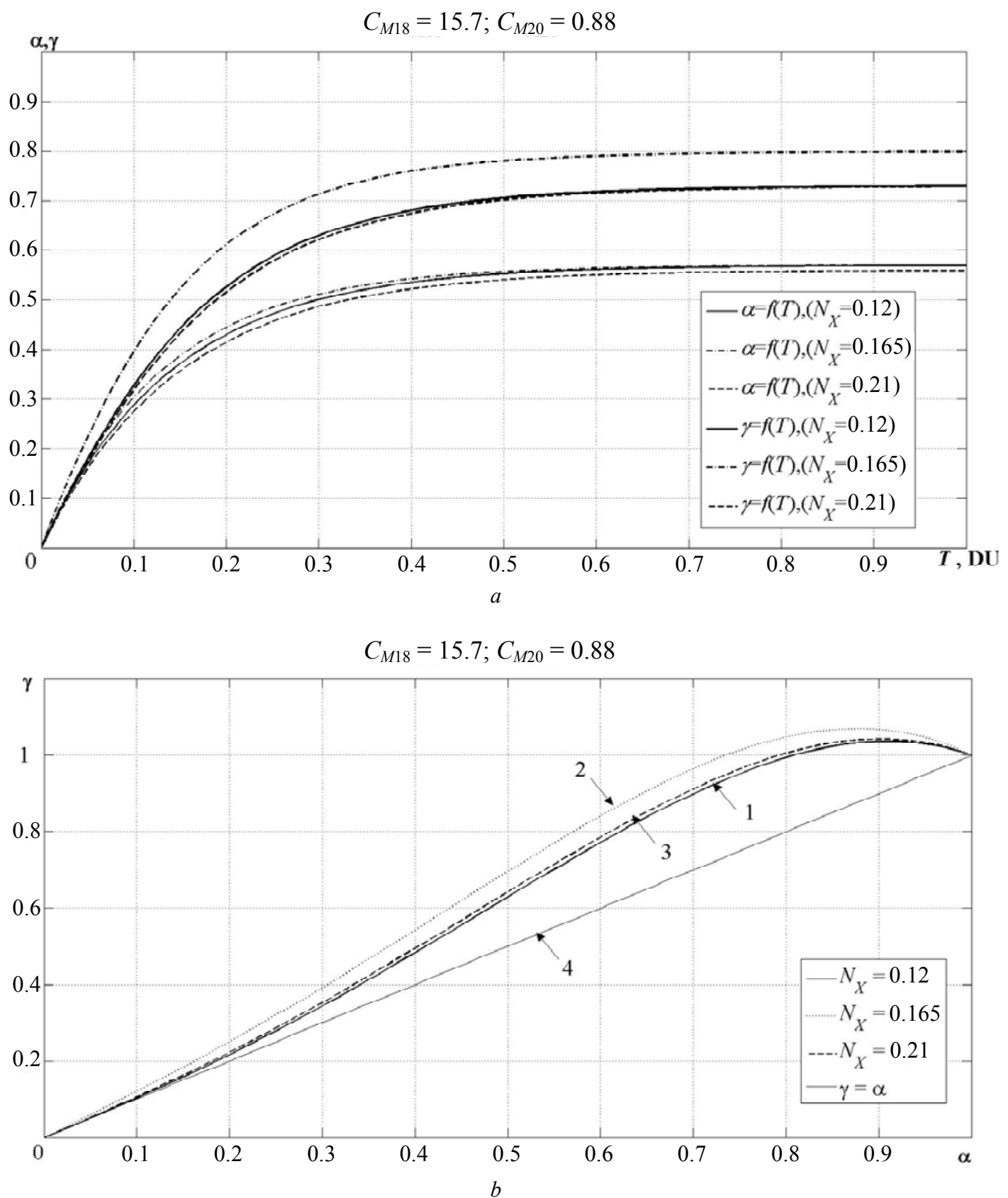

Fig. 2. Optimal control laws by criterion $L_{T \min }\left(v_{\text {prim }}=0.3\right)$

$$
a-\alpha, \gamma=f(T), b-\gamma=f(\alpha)
$$

If maneuvering is carried out in an unrestricted water area, in the absence of other vessels nearby, it makes sense to take the minimum energy losses for the maneuver $W_{\min }$ as the optimality criterion. Most likely, the laws of control will be different. We tried to find them.

In accordance with the conducted studies, the results of which are given in [9], the significantly influencing parameters and by this criterion of optimality (with a contribution level of at least $10 \%$ ) are $v_{\text {prim }}, N_{X}, C_{M 18}$, $C_{M 20}$. Some variants of combinations of these parameters and the optimal solutions found (and $W_{\text {classic }}$ values obtained with the classical $\gamma / \alpha=$ const control law - for evaluating the efficiency of optimization) are given in Table 2.

These control laws can also be graphically illustrated in the same way as was done for optimal control by the criterion of minimum stopping distance. The efficiency (in terms of energy losses) of the proposed control is in the range of $14-34 \%$.

The obtained results can be useful in the very initial stages of the design of propulsion electric power plants. It is already possible at these stages to evaluate the maneuverability characteristics of future electric ships. They can also be useful for vessels in service. For a particular electric ship, in accordance with the goals set, the best control law for propulsion electric motors can be selected and incorporated into the control system.

As an example, consider the project of a particular electric ship. Its main characteristics, necessary for the calculation of the significantly affecting dimensionless parameters $N_{X}, C_{M 18}, C_{M 20}$ are given in Table 3 . 
Table 2

Combinations of significant parameters and found optimal solutions by criterion $W_{\min }\left(v_{\text {prim }}=0.3\right)$

\begin{tabular}{|c|c|c|c|c|c|c|c|c|c|c|c|}
\hline \multirow{3}{*}{ Variant } & \multicolumn{3}{|c|}{$\begin{array}{l}\text { Values of significant } \\
\text { parameters, p.u. }\end{array}$} & \multirow{3}{*}{$\begin{array}{c}W_{\text {classic }}, \\
\text { p.u. }\end{array}$} & \multicolumn{5}{|c|}{ Optimal solutions } & \multirow{3}{*}{$\begin{array}{l}W_{\min }, \\
\text { p.u. }\end{array}$} & \multirow{3}{*}{$\begin{array}{c}\text { Efficiency, } \\
\%\end{array}$} \\
\hline & \multirow[t]{2}{*}{$N_{X}$} & \multirow[t]{2}{*}{$C_{M 18}$} & \multirow{2}{*}{$C_{M 20}$} & & \multicolumn{2}{|c|}{$\begin{array}{c}\text { equations } \\
\alpha=\alpha(T)\end{array}$} & \multicolumn{3}{|c|}{ equations $\gamma=\gamma(\alpha)$} & & \\
\hline & & & & & $K_{1}$ & $K_{5}$ & $K_{2}$ & $K_{3}$ & $K_{4}$ & & \\
\hline 1 & 0.12 & 15.7 & 0.88 & 4.235 & 0.601 & 4.745 & 1.245 & -0.075 & 0.092 & 3.583 & 15.4 \\
\hline 2 & 0.165 & 15.7 & 0.88 & 3.527 & 0.590 & 1.052 & 1.117 & 0.092 & 0.721 & 2.993 & 15.1 \\
\hline 3 & 0.21 & 15.7 & 0.88 & 2.92 & 0.576 & 6.149 & 1.231 & 0.014 & 1.351 & 2.522 & 13.6 \\
\hline 4 & 0.12 & 43.9 & 0.88 & 4.41 & 0.591 & 1.432 & 1.363 & 0.147 & 1.451 & 3.549 & 19.5 \\
\hline 5 & 0.165 & 43.9 & 0.88 & 3.573 & 0.526 & 4 & 1.31 & 0.378 & 2.07 & 2.774 & 22.4 \\
\hline 6 & 0.21 & 43.9 & 0.88 & 3.063 & 0.526 & 4.33 & 1.31 & 0.378 & 2.07 & 2.36 & 23 \\
\hline 7 & 0.12 & 72 & 0.88 & 4.59 & 0.569 & 4.5 & 1.397 & 0.199 & 1.106 & 3.492 & 23.9 \\
\hline 8 & 0.165 & 72 & 0.88 & 3.74 & 0.575 & 4.507 & 1.367 & 0.193 & 1.092 & 2.937 & 21.5 \\
\hline 9 & 0.21 & 72 & 0.88 & 3.1 & 0.53 & 5.1 & 1.31 & 0.38 & 2.07 & 2.36 & 23.9 \\
\hline 10 & 0.12 & 15.7 & 0.925 & 4.083 & 0.615 & 5.97 & 1.239 & -0.0007 & 0.738 & 3.372 & 17.4 \\
\hline 11 & 0.165 & 15.7 & 0.925 & 3.416 & 0.662 & 1.421 & 1.304 & 0.154 & 1.468 & 2.824 & 17.3 \\
\hline 12 & 0.21 & 15.7 & 0.925 & 2.836 & 0.5 & 5.31 & 1.216 & 0.4 & 2.9 & 2.29 & 19.3 \\
\hline 13 & 0.12 & 43.9 & 0.925 & 4.247 & 0.631 & 1.433 & 1.375 & 0.159 & 1.448 & 3.335 & 21.5 \\
\hline 14 & 0.165 & 43.9 & 0.925 & 3.458 & 0.53 & 3.98 & 1.31 & 0.328 & 2.17 & 2.3 & 33.5 \\
\hline 15 & 0.21 & 43.9 & 0.925 & 2.97 & 0.53 & 4.43 & 1.31 & 0.38 & 2.07 & 2.3 & 22.6 \\
\hline 16 & 0.12 & 72 & 0.925 & 4.417 & 0.635 & 6.181 & 1.334 & 0.131 & 1.251 & 3.273 & 25.9 \\
\hline 17 & 0.165 & 72 & 0.925 & 3.62 & 0.633 & 6.74 & 1.249 & 0.005 & 1.323 & 2.764 & 23.6 \\
\hline 18 & 0.21 & 72 & 0.925 & 3.00 & 0.636 & 6.669 & 1.36 & 0.131 & 1.161 & 2.354 & 21.5 \\
\hline 19 & 0.12 & 15.7 & 0.97 & 3.93 & 0.633 & 3.976 & 1.276 & 0.058 & 1.529 & 3.199 & 18.6 \\
\hline 20 & 0.165 & 15.7 & 0.97 & 3.31 & 0.642 & 2.696 & 1.224 & 0.011 & 1.251 & 2.696 & 18.5 \\
\hline 21 & 0.21 & 15.7 & 0.97 & 2.843 & 0.62 & 4.87 & 1.22 & 0.28 & 1.56 & 2.27 & 20.2 \\
\hline 22 & 0.12 & 43.9 & 0.97 & 4.08 & 0.658 & 8.523 & 1.053 & -0.006 & 1.48 & 3.189 & 21.8 \\
\hline 23 & 0.165 & 43.9 & 0.97 & 3.35 & 0.666 & 5.426 & 1.285 & 0.036 & 0.56 & 2.677 & 20.1 \\
\hline 24 & 0.21 & 43.9 & 0.97 & 2.873 & 0.57 & 4.45 & 1.3 & 0.586 & 1.03 & 2.24 & 22 \\
\hline 25 & 0.12 & 72 & 0.97 & 4.235 & 0.666 & 4.546 & 1.417 & -0.028 & 0.775 & 3.16 & 25.4 \\
\hline 26 & 0.165 & 72 & 0.97 & 3.492 & 0.56 & 4 & 1.31 & 0.33 & 2.17 & 2.61 & 25.3 \\
\hline 27 & 0.21 & 72 & 0.97 & 2.91 & 0.47 & 3.16 & 1.38 & 0.46 & 2.48 & 2.16 & 25.8 \\
\hline
\end{tabular}

Table 3

Table 4

Main characteristics of the electric ship

\begin{tabular}{|l|c|}
\hline The length of the vessel at the waterline, $L$ & $160 \mathrm{~m}$ \\
\hline Ship velocity in steady state, $v_{0}$ & $22 \mathrm{knots}$ \\
\hline Vessel mass, $m$ & $33540 \mathrm{t}$ \\
\hline Total stop of propellers, $\sum K_{p j} P_{e j 0}$ & $\begin{array}{c}6250 \\
\mathrm{t} \cdot \mathrm{m} / \mathrm{s}^{2}\end{array}$ \\
\hline $\begin{array}{l}\text { Attached to the vessel the masses of water along } \\
\text { its longitudinal axis, } \lambda_{11}\end{array}$ & $0.11 \mathrm{t}$ \\
\hline Angular velocity of the PM rotation, $\omega_{M}$ & $120 \mathrm{rpm}$ \\
\hline $\begin{array}{l}\text { Angular velocity of the PM stator magnetic field } \\
\text { rotation, } \omega_{1 M n}\end{array}$ & $124 \mathrm{rpm}$ \\
\hline Constant design factor, $c_{M}$ & $0.423 \Omega$ \\
\hline Reduced resistance of the PM rotor, $r_{2 M}^{\prime}$ & $0.0639 \Omega$ \\
\hline
\end{tabular}

The numerical values of significant parameters calculated from the above relations are given in Table 4.
Values of the dimensionless electric ship parameters

\begin{tabular}{|c|c|}
\hline Parameter & Numerical values of the parameters \\
\hline$N_{X}$ & 0.21 \\
\hline$C_{M 18}$ & 43.9 \\
\hline$C_{M 20}$ & $0 . .97$ \\
\hline
\end{tabular}

For this combination of parameters - for this electric ship -the optimal law of control of the propulsion electric motors providing the minimum stopping distance $L_{T \min }$ will be option 24 of the Table 1. Namely:

$$
\begin{gathered}
\alpha=0.1+0.65(1-\exp (-6.17 T)) \\
\gamma=1.19 \alpha+0.2 \alpha^{2}+0.85 \alpha^{3}-1.24 \alpha^{4} .
\end{gathered}
$$

It is these laws of control of the relative frequency $\alpha$ and relative voltage $\gamma$ that are recommended to be inserted into the control system of the propulsion electric motors, if it is necessary to ensure the minimum stopping distance of the electric ship when reversed. Here, it will be 0.26 of the vessel length, or in absolute units $-41.6 \mathrm{~m}$.

If we apply the traditional proportional control law, the stopping distance will be 0.33 vessel length, or in absolute units $-52.8 \mathrm{~m}$. Thus, the effectiveness of applying the recommended optimal control law is $21.2 \%$. 
The results obtained can be illustrated graphically. Fig. 3 shows the curves of the time variation of the relative frequency $\alpha=f(T)$ and the relative voltage $\gamma=f(T)$ (Fig. 3,a), as well as the dependencies (Fig. 3,b) of the optimal control law $\gamma=f(\alpha)$ when reversing PM of an electric ship moving at a low speed (at initial speed $v_{\text {prim }}=0.3$ ) and proportional (for comparison with the optimal) control law $\gamma_{0}=f(\alpha)$.
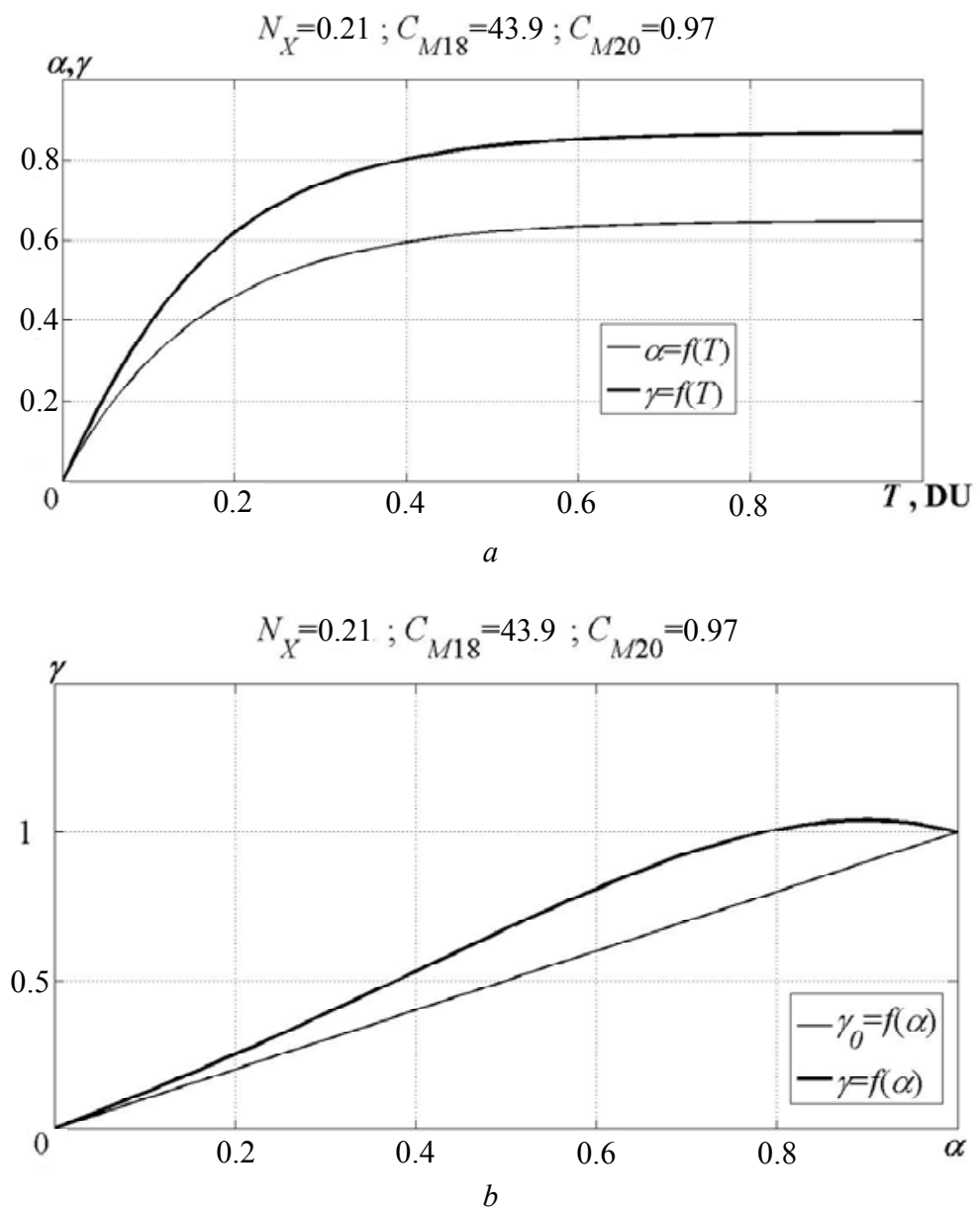

Fig. 3. Optimal control laws (for the project of an electric ship) by criterion $L_{T \min }$ (at $v_{\text {prim }}=0.3$ ):

$$
a-\alpha, \gamma=f(T), b-\gamma=f(\alpha)
$$

If the reversal is carried out in unfilled conditions and it is advisable to ensure a minimum of energy consumption, then the optimal control law of this electric ship will be the same option 24 , but from Table 2. The control laws in this case:

$$
\begin{gathered}
\alpha=0.1+0.57(1-\exp (-4.45 T)) \\
\gamma=1.3 \alpha+0.586 \alpha^{2}+1.03 \alpha^{3}-1.916 \alpha^{4} .
\end{gathered}
$$

When controlled by these laws, energy consumption is reduced compared to the classic version from 2.873 to 2.24 relative units.

If necessary, laws can be clarified. To do this, it is necessary to substitute the numerical values of the dimensionless parameters of the complex into the mathematical model and calculate, using the developed method, the optimal control law (now refined) with the appropriate optimality criterion. However, it is advisable to do this already at the later design stages, in the presence of more complete information about the designed ship.

\section{Conclusions.}

1. It has been established that the traditional principles of constructing optimal control laws for frequencycontrolled induction electric motors of electric ships do not allow to obtain the maximum return from the propulsion electric power plant. A new method of forming optimal laws, based on a systematic principle, is proposed.

2. The nature of the target functions is identified, a technique of optimization is developed. The procedure of optimization calculations is proposed.

3. Optimization calculations were carried out and optimal control laws for propulsion electric motors were found at the reverse of electric ships. Optimization was carried out according to the criteria of minimum stopping distance and minimum power consumption.

4. The effectiveness of using the proposed control laws is illustrated.

\section{REFERENCES}

1. Yarovenko V.A. Raschet $i$ optimizatsiia perekhodnykh rezhimov propul'sivnykh kompleksov elektrokhodov [Calculation and optimization of transient regimes of propulsion complexes of electric vessels]. Odessa, Mayak Publ., 1999. 188 p. (Rus).

2. Yarovenko V.A., Chernikov P.S. A calculation method of transient modes of electric ships' propelling electric plants. Electrical engineering \& electromechanics, 2017, no.6, pp. 32-41. doi: 10.20998/2074-272X.2017.6.05. (Rus). 
3. Sukharev A.G., Timokhov A.V., Fedorov V.V. Kurs metodov optimizatsii [Course of optimization methods]. Moscow, Fizmatlit Publ., 2005. 368 p. (Rus).

4. Bonnans J.-F., Gilbert J.C., Lemarechal C., Sagastizábal C.A. Numerical optimization: theoretical and practical aspects. Berlin, Heidelberg: Springer-Verlag, 2006. 494 p. doi: 10.1007/978-3-662-05078-1.

5. Fletcher R. Practical Methods of Optimization. Wiley, 2000. 450 p. doi: 10.1002/9781118723203.

6. Antoniou A., Lu W.-S. Practical optimization. Algorithms and engineering applications. Springer, 2007. 675 p.

7. Floudas C.A., Pardalos P.M. Encyclopedia of optimization. Springer, 2009. 4646 p. doi: 10.1007/978-0-387-74759-0.

8. Panteleev A.V., Letova T.A. Metody optimizatsii $v$ primerakh $i$ zadachakh [Optimization methods in examples and problems]. Moscow, High school Publ., 2008. 544 p. (Rus).

9. Chernikov P.S., Yarovenko V.A., Zaritskaya E.I. Influence of electric ships' parameters on quality indices of electric power plants' performance at maneuvers. Bulletin of the National Technical University «KhPI» Series: «Electric machines and electromechanical energy conversion», 2018, no.5(1281), pp. 46-54. (Rus).

Received 31.07.2018

V.A. Yarovenko ${ }^{1}$, Doctor of Technical Science, Professor, P.S. Chernikov ${ }^{1}$, Senior Instructor,

R.A. Varbanets ${ }^{1}$, Doctor of Technical Science, Professor,

E.I. Zaritskaya ${ }^{1}$, Candidate of Technical Science, Associate Professor,

${ }^{1}$ Odessa National Maritime University,

34, Mechnikova Str., Odessa, 65007, Ukraine, phone +380505980683 ,

e-mail: yarovenko@3g.ua, chernikov@onmu.odessa.ua, roman.varbanets@gmail.com, zarickayalena@ukr.net

How to cite this article:

Yarovenko V.A., Chernikov P.S., Varbanets R.A., Zaritskaya E.I. Optimal control of the electric ships' propulsion motors during reversal. Electrical engineering \& electromechanics, 2018, no.6, pp. 38-46. doi: 10.20998/2074272X.2018.6.05. 